Acta Poetica $35 \cdot 2$

JULIO-DICIEMBRE

$2014(137-147)$

\title{
El viaje como expresión del misticismo en Segundo sueño de Sergio Fernández
}

\author{
Claudia Ramos
}

En este artículo se analiza la relación que puede establecerse entre los sueños de anábasis del poema de sor Juana Inés de la Cruz, Primero sueño, y la novela de Sergio Fernández, Segundo sueño, en una concordancia donde el alma, durante su viaje por las esferas supra lunares, o en la transmutación de los elementos naturales - la lluvia, la nieve y el lodo-, experimenta el misterio de su encuentro con lo divino como un proceso de iniciación.

En el poema, la búsqueda del conocimiento supremo es una trampa; en la novela, la encrucijada se halla en el erotismo transgresor. Estos dos viajes de anábasis traducen el guiño que anuncia la sucesión en una caída. En ambos casos, la desmesura del alma, máscara de un héroe trágico, derrite las alas de Ícaro y propicia la muerte de Faetón, el auriga inexperto del carro divino.

Palabras clave: Sueños de anábasis, alma, Primero sueño, Segundo sueño, sor Juana Inés de la Cruz, Sergio Fernández, misticismo, proceso de iniciación, hybris, caída, héroe trágico.

In this article the relationship which can be established between the dreams of Anabasis in sor Juana Inés de la Cruz's poem, Primero sueño and the novel by Sergio Fernández, Segundo sueño, is analized in a concordance where the soul during its journey through the supra lunar spheres, or in the transmutation of natural elements - rain, snow and mud-, experiences the mystery of its encounter with the divine as a process of initiation.

In the poem, the pursuit of higher knowledge is a trap; in the novel, the crossroads is found in the transgressive eroticism. These two trips of anabasis, the first and the second dream, translate the wink announcing the succession in a fall. In both cases, the excess of the soul, a tragic hero mask, melts the wings of Icarus and conduces to the death of Phaeton, the death of the inexperienced charioteer of the divine chariot. 
KeYwORDs: Trips of anabasis, soul, Primero Sueño, Segundo sueño, sor Juana Inés de la Cruz, Sergio Fernández, mysticism, process of initiation, hybris, fall, tragic hero.

Fecha de recepción: 17 de mayo de 2013

Fecha de aceptación: 7 de diciembre de 2013 
Claudia Ramos

Universidad Nacional Autónoma de México

Posgrado en Letras

\section{El viaje como expresión del misticismo en Segundo sueño de Sergio Fernández}

Hic situs est Phaethon currus auriga paterni

[Aquí enterrado está Faetón, auriga del carro paterno]

Ovidio, Metamorfosis, II, 328

La diversidad de personas y experiencias que se acumulan en el encuentro de los días, y el someterse a las pruebas de las circunstancias son propias del viaje. Hay distintas formas de viajar: el traslado vertiginoso de un sitio a otro o la contemplación estática de las horas; se viaja durante el sueño o la vigilia; en la claridad diáfana de la conciencia o en los estados alterados propicios al inconsciente; viaja el cuerpo con el alma, también lo hacen por separado: el cuerpo inmóvil frente al alma solitaria. Difícilmente el cuerpo se aventura solo, desalmado; si se atiende el consejo de Platón en el Timeo, no mover el cuerpo sin el alma ni el alma sin el cuerpo, sino procurar que ambos guarden un equilibrio para mantener, así, la salud (88b), podría suponerse que la aventura del alma solitaria supone ya un viaje distinto, el que transita por la enfermedad, y supone una caída.

Larga es la tradición de los sueños de anábasis, donde el alma se aventura mientras el cuerpo duerme; viaja acompañada de un guía, tal vez, para equilibrar la ausencia del cuerpo y recordar el vínculo. "Cuando en el sueño, el alma se separa del cuerpo [escribe Cicerón en 
Sobre la adivinación] y no está en contacto con él, recuerda el pasado, mira el presente, prevé el futuro [...] cuando ha abandonado el cuerpo enteramente, el alma es mucho más divina" (I, 63). La cercanía del alma con lo divino la coloca en la zona liminal del misterio, lo numénico por antonomasia, el ámbito de lo sagrado.

Propio del viaje que realiza el alma fuera del cuerpo es, pues, la iniciación en los misterios, el misticismo. Del adjetivo griego mysticós, el alma, así descrita, busca un estado de unión inefable con la divinidad; con ese Otro que lo es en absoluto. Como todo viaje, esta iniciación implica movimiento, una manera de abandonar el rutinario ser y estar en el mundo para encontrarse con la alteridad y en la alteridad; encontrarse con el otro siendo, uno mismo, otro.

En la novela que nos ocupa, Segundo sueño (1976), de Sergio Fernández, el viaje del alma se anuncia como una continuidad. Si se habla de un "segundo" tuvo que existir un "primero". La novela no se titula el sueño, los sueños o primero sueño. La relación que la obra del escritor mexicano establece con sor Juana Inés de la Cruz, nos indica que el posible antecedente de ese segundo sueño, sea el primero de la monja jerónima:

Las referencias que [de sor Juana] se hacen en Segundo sueño - advierte Sergio Fernández - lo son tanto íntima y humanamente como por una relación de otro orden, acaso metafísico, que no la descarna. Este doble horizonte va más allá del ámbito literario pero en él encuentra su base. Por otra parte, si he escrito esta novela es como una vinculación reveladora para mí, ya que intenta expresar los silencios de la monja y cristalizarlos en mi escritura. Dicho de otro modo (y aunque pueda oler a vanidad) hay párrafos que a mi parecer, a ella le hubiera gustado decir y no lo hizo por la mordaza de su siglo. Las cosas que se dicen en Segundo sueño muy bien pueden ser atribuidas a la persona moral que le atribuyo a sor Juana. He intentado pues llenarme de esos ecos que provienen de ella, que son ella (Volkow y Bravo, "Conversación”, 12).

Entonces, Segundo sueño puede escucharse, por momentos, como el eco de lo que sor Juana se vio en la necesidad de enmascarar. Sin pretender que la configuración de la novela se base en la premisa de continuar la obra inconclusa de sor Juana, ha de advertirse que ambos 
viajes son concordantes, no discordantes. En ambos viajes existe una continuidad de tipo literario, no filosófico o histórico, cuya relación se encuentra en el sentido transgresor de la experiencia mística.

El viaje en Segundo sueño se da en varios sentidos: el cuerpo del narrador viaja de México a Alemania para dar un curso de arte y escribe (otro modo de viajar) la biografía de un pintor renacentista, Lucius Altner (una alteridad absoluta) y su propio libro de memorias (otra alteridad confrontante). Además, a pesar de la rebeldía que le inspira, va siguiendo la voz de su madre, que, a modo de guía, como en un sueño de anábasis, tira las cartas del tarot egipcio para indicar los escollos y augurar siempre el peor de los finales.

Sergio Fernández prologa su novela para explicar el sentido hermético que la fundamenta, el misticismo de su estructura onírica: "Este libro [dice] está construido sobre varias leyes mágicas, una de las cuales acaso sea necesario explicar: todo hombre ignora, claro, lo que habrá de pasar (en su encuentro con circunstancias y personas), pero de algún modo lo sabe, pues ha nacido para que suceda" (Segundo sueño, 7).

No sólo el tarot egipcio; entre los registros que fundamentan el misticismo del viaje onírico se encuentran, en el índice capitular, la alusión a la Cábala, la Astrología y el Libro de los muertos. En la concepción religiosa del antiguo Egipto, la muerte era una forma de viaje al más allá. El libro de los muertos es un compendio de fórmulas mágicas e invocaciones a las divinidades que debía pronunciar el difunto para obtener ayuda en las pruebas y trabajos de su paso por las regiones de la muerte - la morada de Osiris - y lograr, finalmente, la resurrección: un nuevo nacimiento.

Este nuevo nacimiento, la unión final con lo divino, ocurre tras un proceso donde el sueño, el erotismo, la creación y la escritura llevan al narrador al encuentro con un espejo alquímico que lo enfrentará, una y otra vez, con el misterio que es el conocimiento de sí mismo, la alteridad simbolizada en su propio desvelo.

La disposición estructural divide a la novela en dos registros distintos. La primera parte - La lluvia, la nieve y el lodo- corresponde al sueño y a la confusa somnolencia que se presenta al momento de despertar. La segunda parte - Una reiteración: la lluvia, la nieve y el lodo - se identifica con la completa vigilia, cuando el narrador es capaz 
de contar a su madre los sucesos del sueño recreando a favor de su deseo las imágenes oníricas.

Este viaje iniciático da cabal cumplimiento a una acción oculta que pronunciada por la madre como sentencia se convierte para el narrador en mandato: "En Alemania te encontrarás con el demonio" (Volkow y Bravo, "Conversación", 11). Sirena de cantos fúnebres, esta madre guía el alma de su hijo hacia el retorno de su amantísimo y bivalente seno.

Sergio Fernández afirma que fue María Zambrano quien inspiró el personaje de esta madre terrible que conduce a su hijo al encuentro con el mal:

A María Zambrano la conocí en Roma. [...] Me dijo que no fuera a Alemania (donde intentaba dar un curso) pues me iba a encontrar con el demonio. Ésta fue la fórmula que desató Segundo sueño [...]. María se convirtió en una madre monstruosa, me señalaba el mal pero, al propio tiempo, no tenía o no quería tener la fuerza para que yo - ingenuo- no fuera hasta sus brazos [...]. Podría decirse en términos románticos, que María es la fuente de inspiración del personaje en cuanto tal, por más que tenga rasgos de las madres que todos padecemos (11).

En Segundo sueño, el viaje del alma como expresión del misticismo es el personaje principal. Entendido como destino, este viaje se traduce en un sentido de "libre albedrío negativo". El narrador escoge la fatalidad que se anuncia en los arcanos, entrega a priori la trama y se dedica a recrearse, una y otra vez, en los elementos que, a modo de máscara, darán forma a su mito personal: el desafío en oposición a la obediencia; el desconcierto del alma que sólo encuentra en el obstinado recorrido el ofuscamiento del desamor y la vuelta a la vigilia materna.

¿Será que la advertencia de Platón en el Timeo, "no mover el cuerpo sin el alma y el alma sin el cuerpo", tendría que considerarse con más atención, y los viajes del alma con más cautela? La cercanía con lo divino, si bien coloca al alma en un estado de revelación privilegiada, también trae consigo la hybris, esa soberbia que lleva a todo héroe a caer en hamartía, el error trágico que desencadena la fatalidad.

En el posible antecedente de este Segundo sueño, el Primero sueño de sor Juana, el alma se despeña, también, desde una hybris donde pre- 
valece el empeño por abarcar el conocimiento del mundo. Siguiendo la interpretación de Octavio Paz, esta caída se trata de la "confesión que termina en un acto de fe: no en el saber, sino en el afán de saber" (Sor Juana Inés de la Cruz, 499), pero ¿no es esta épica del conocimiento un acto en sí mismo transgresor frente a la divinidad? El alma que confía en los medios de su entendimiento deja de entregarse a la revelación y se despeña en una vigilia de vértigo conceptual: la revelación de la norevelación (cfr. Paz, México en la obra, 500).

Sor Juana se inicia en el misterio del mundo también por medio de un viaje plasmado en "un papelillo que llaman el sueño"; así se refiere en la Respuesta a Sor Filotea de la Cruz al texto que, en una edición posterior, llamará Primero sueño, que así intituló y compuso la madre Juana, imitando a Góngora. En opinión de Paz, el adjetivo "primero" despierta la sospecha de que sor Juana pensaba escribir un segundo sueño, de ahí la alusión a Góngora, autor de dos Soledades, la primera y la segunda. Sin embargo, dadas las diferencias con el poeta barroco, Octavio Paz se inclina por el viaje inconcluso, el desafío que no ceja y se homologa a la actitud de los dos héroes que despeñan, igual que el alma, rebelde y desafiante: Ícaro y Faetón (469-507).

Propio del héroe trágico es la caída, el error, la hamartía, porque en su condición de semi-dios, que no es hombre propiamente y no termina de ser dios, busca ser y tener más. Épico por excelencia, quiere trascenderse, transgredir, ir más allá de los límites. Esta actitud soberbia lo convierte en hybristes, es decir, la fuerza que inicia el desequilibrio en el estado natural de las cosas. Tal es el caso de Ícaro y Faetón, alegorías del alma de sor Juana.

La altura propicia la caída. Los versos 466-468 de Primero sueño hacen alusión a Ícaro y a su padre Dédalo, quienes atrapados en el laberinto de Minos que el propio Dédalo construyó, escaparán de este artificio con otro: la construcción de unas alas con cera y plumas para salir volando. Dédalo descuidó los consejos de su padre — no volar demasiado alto porque el calor del sol derretiría la cera, ni demasiado bajo porque la espuma del mar mojaría las alas-, se acercó durante su vuelo peligrosamente al sol. Las alas funcionaban perfectamente a una distancia mesurada, como lo aconseja el oráculo de Delfos, "nada en demasía”. La juventud, tan proclive al exceso, llevó a Ícaro al peligroso 
ascenso. La cera comenzó a derretirse y las plumas se despegaron. Ícaro cayó al mar y murió al despeñarse (Ovidio, Metamorfosis, 195-235).

Por su parte Faetón, el hijo del Apolo —en la versión de Hesíodo es hijo de Helios, el sol (cfr. Hesiodo, Teogonía, 986; Apolodoro, Biblioteca mitológica, III, 14, 4), que después tomaría el adjetivo de Febo, el brillante, como se conoce a Apolo en la Metamorfosis de Ovidio, texto que leyó sor Juana (Pérez-Amador, El precipicio de Featón, 213)—, quiere demostrar a los incrédulos que él es, en efecto, hijo de Apolo; le pidió a su padre jurar sobre la Estigia (un juramento al que ni los dioses pueden faltar) que cumpliría un deseo suyo, cualquiera que éste fuese. El padre jura, y con su juramento pierde la oportunidad de proteger a Faetón de su desmesura. El hijo solicita entonces las riendas del carro del sol; Apolo trata de persuadirlo, pero es inútil, Faetón está decidido, por algo es el hijo de un dios. Los caballos se desbocan, a Faetón le es imposible controlar el curso del carro del sol, incendia la Tierra, y cuando el peligro va ascendiendo a los confines del cielo, Zeus lo fulmina con un rayo. El auriga del carro paterno se precipita al fondo del mar (Ovidio, Metamorfosis, II, 32-328).

La experiencia del despeño es lo que el alma contempla y padece en su viaje como expresión del misticismo. Es un alma épica, soberbia. Se ha desprendido del cuerpo que ha caído en un pesado dormir y está lleno de noche. El alma, igual que Ícaro y Faetón, asciende, se eleva hasta que deja de ver los alcances de sus propios límites. Se inicia en el misterio, quiere contemplar el universo, ¿por qué no?, es un alma heroica. De la primera caída se levanta y vuelve a intentar el ascenso, ahora más paciente, no por eso mesurada. La intuición de un conocimiento final, la revelación de algo que le muestre, de una vez por todas, la totalidad del mundo, la impulsa.

A diferencia de la tradición de los sueños de anábasis, el alma de sor Juana va sin guía; no hay dios, demiurgo ni antepasado muerto que le indique el camino: sola se despeña, sola prevalece; sola se enfrenta a la revelación de lo no revelado. Sin embargo, no hay algo que indique que la aventura ahí termina. Si hay un primero sueño, bien puede haber un segundo y un tercero, ¿qué lo impide?

Primero sueño, en la definición de Octavio Paz, es "la alegoría de una experiencia que no puede encerrarse en el espacio de una noche, 
sino de muchas que pasó sor Juana estudiando y pensando" (168). En este sentido, la Respuesta a Sor Filotea sería el complemento de Primero sueño, la versión histórica, el relato en prosa donde figura la misma obsesión: la búsqueda del conocimiento, sólo que ahora la obsesión se despliega en el espacio de una vida. Si se une la experiencia de la prosa y el verso, el viaje de sor Juana seguirá entre la bivalencia de la revelación de lo no revelado: en su sueño no da constancia de la veracidad de lo soñado, porque el verso es el lenguaje predilecto de la ficción, pero una vez que el mundo se ha iluminado, la prosa sí es testimonio de la gran pasión del alma.

También en el viaje de Segundo sueño se unen la historia y la ficción, la prosa y el verso. En esta novela lírica la dimensión poética e histórica de Primero sueño y de la Respuesta a Sor Filotea de la Cruz se integran en un movimiento oscilatorio que se debate entre la invención y "la realidad", entre el rostro y el afeite. El proceso autobiográfico de los tres libros que conforman Segundo sueño: la biografía de Lucius Altner, las memorias del protagonista y la narración de su viaje a Alemania dan cuenta del juego que se mueve en un plano alegórico y confesional al mismo tiempo. Segundo sueño es el reflejo de su propia configuración y, como en Primero sueño y la Respuesta a Sor Filotea de la Cruz, revela los pliegues, los silencios del proceso creativo del artista.

El carácter impersonal del sueño es otra coincidencia; tal como sucede en el proceso de iniciación, en el camino que lleva hacia el misterio: las almas viajan sin nombre. El protagonista, en ambos casos, es un ser enmascarado. Aunque en Primero sueño el anonimato del alma se pierde en el verso final: "quedose el mundo iluminado y yo despierta" - cuando se asume que se trata del alma de sor Juana-, la impersonalidad del poema no se altera: las almas, lo dijo sor Juana una y otra vez, "no tienen sexo" (Paz, México en la obra, 160).

En Segundo sueño el anonimato no se pierde en ningún momento, el protagonista, escondido tras la figura del misterioso pintor y el erotismo bisexual y pederasta de un alma bivalente — parodia de su equívoca asexualidad - reserva el secreto de su identificación. En ambos sueños, el gusto por la máscara acentúa el carácter alegórico del viaje onírico, la experiencia mística, entonces, no la vive un hombre en particular: es el 
Hombre quien se inicia, una y otra vez, en ese movimiento del alma que busca el encuentro con lo divino.

En Segundo sueño el alma, despeñada, tiene por guía a una madre terrible que a través del tarot advierte los peligros sólo para atraer al alma hacia ellos. Su voz seduce, provee los medios necesarios para la satisfacción de placeres mundanos, sugiere mañas y artimañas en el juego de la perversión y, finalmente, propicia el encuentro con el mal, con el demonio - lo que podría sospecharse como el último placer, el éxtasis de toda revelación-; sin embargo, el alma concluye su viaje en la misma situación que en el sueño de sor Juana: la soledad más absoluta, el silencio mineral.

Así pues, Segundo sueño, como expresión de un viaje místico, encuentra en el Primero sueño de sor Juana el eco de sus misterios; asemejándose al poema, se encubre en un laberinto de oscuridad y recovecos - metáfora barroca - otorgando al texto un movimiento incesante. Segundo sueño enmascara la realidad hasta convertirla en arte; máscara sobre máscara que encubre y devela, al igual que Primero sueño, los más profundos abismos del alma humana.

Ambas obras están imbuidas de la experiencia mística del viaje como proceso de iniciación en cuyo desequilibrio sucumbe el alma; al moverse sin el cuerpo se acerca a lo divino, y en este trastrocamiento se encuentra con el peligro, siempre inminente, de caer despeñada del carro del sol.

\section{REFERENCIAS}

Cicerón, Marco Tulio, Sobre la adivinación. Sobre el destino. Timeo. Traducción, introducción y notas, Ángel Escobar, Madrid, Gredos, 2000.

Cruz, sor Juana Inés de la, Obras completas, Tomo I: Lírica personal, MéxicoBuenos Aires, Fondo de Cultura Económica, 1951.

Fernández, Sergio, Segundo sueño, México, Joaquín Mortiz, 1976.

Ovidio. Metamorfosis en Perseus Collection. Greek and Roman Materials $<$ www.perseus.tufts.edu/hopper/text;jessionid=58183D1D29B63OC5D1 B7B33F9BA9449C?doc=Perseus\%3Atext\%3A1999.02.0028\%Abook\% 3D2\%Acard\%3D1>. 
PAz, Octavio, Sor Juana Inés de la Cruz o las trampas de la fe, México, Fondo de Cultura Económica, 1982.

Paz, Octavio, México en la obra de Octavio Paz, México, Fondo de Cultura Económica, 1987.

Pérez-Amador Adam, Alberto, El precipicio de Featón. Nueva edición, estudio filológico y comento de 'Primero sueño' de Sor Juana Inés de la Cruz, Frankfurt-Madrid, Ediciones de Iberoamericana, 1996.

Perseus Collection, Greek and Roman Materials. <http://www.perseus.tufts. edu/hopper/collection?collection=Perseus:collection:Greco-Roman> [15/05/2013].

Ramos Aguilar, Claudia, La noción de mal en 'Segundo sueño' de Sergio Fernández, México, Universidad Nacional Autónoma de México, 2000.

VolKow, Verónica y Víctor Bravo, “Conversación con Sergio Fernández: 'Lo insignificante que se convierte por su propio peso literario en lo maravilloso'", Sábado 78, 1979, 11-12. 